\title{
A novel tetrameric lectin from Lycoris aurea with four mannose binding sites per monomer ${ }^{\star}$
}

\author{
Jiwei Liu ${ }^{1}$, Xiaochao $\mathrm{Xu}^{1}$, Jinzhi Liu ${ }^{1}$, Jan Balzarini ${ }^{2}$, Yongtin Luo ${ }^{1}$, Yang Kong ${ }^{1}$, \\ Jian $\mathrm{Li}^{1}$, Fang Chen ${ }^{1}$, Els Van Damme ${ }^{3}$ and Jinku Bao ${ }^{1 凶}$ \\ ${ }^{1}$ College of Life Sciences, Sichuan University, Chengdu, P. R. China; ${ }^{2}$ Rega Institute for Medical Research, \\ K. U. Leuven, Belgium; ${ }^{3}$ Department of Molecular Biotechnology, Ghent University, Gent, Belgium
}

Received: 27 November, 2006; revised: 20 February, 2007; accepted: 05 March, 2007

available on-line: 14 March, 2007

\begin{abstract}
The mannose-binding agglutinin from bulbs of Lycoris aurea (LAA) agglutinates rabbit but not human erythrocytes. The molecular mass of the monomer in SDS/PAGE is $12 \mathrm{kDa}$ while the apparent molecular mass in gel filtration is $48 \mathrm{kDa}$, indicating that LAA is a homotetramer. The full-length cDNA of LAA contains $683 \mathrm{bp}$ with an open reading frame encoding a protomer of 162 amino-acid residues. Hydrophobic Cluster Analysis and molecular modeling of the 109-residue mature polypeptide suggested a similar secondary and tertiary structure to those of Narcissus pseudonarcissus agglutinin (NPA). Molecular docking revealed that, besides the three mannosebinding sites common among Amaryllidaceae lectins, LAA also contains a fourth unique mannose-binding site formed by a tryptophan cluster. The existence of four mannose-binding sites in each monomer of LAA is very unusual and has only been reported for NPA earlier.
\end{abstract}

Keywords: Lycoris aurea agglutinin, sequence alignment, mannose-binding lectin, molecular modeling and docking

\section{INTRODUCTION}

Numerous plant species accumulate proteins possessing one or more domains that recognize and bind specific carbohydrates, with no catalytic properties. Since 1987, the description of the first monocot mannose-binding lectin (MBL) from snowdrop bulbls, more monocot MBLs have been isolated and cloned from various tissues of families Alliaceae, Amaryllidaceae, Araceae, etc. Evidence has accumulated that all monocot MBLs reported to date consist of subunits with highly homologous sequences and overall similar tertiary structures, which suggests the existence of a single superfamily of mannose- binding proteins (Barre et al., 1996; Van Damme et al., 2000).

Hitherto, monocot MBLs have already attracted a lot of attention in different scientific fields because of their interesting biological properties, such as the suppressive effect on (retro)viruses and the toxic effect against insects and nematodes (Van Damme et al., 1998). Recently, MBLs, isolated from several Amaryllidaceae species such as Galanthus nivalis, Narcissus pseudonarcissus and Lycoris radiate were shown to exhibit inhibitory effect on sap-sucking insects including aphids and planthoppers when tested in artificial diet assays. However, the major field of interest in MBLs is in biomedical research

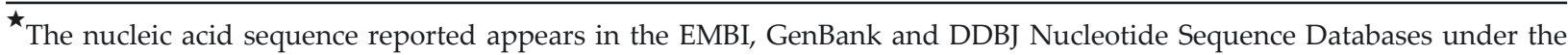
accession number AY763112.

${ }^{\square}$ Corresponding author: Jinku Bao, College of Life Sciences, Sichuan University, Chengdu, 610064, P. R. China; tel.: (86 28) 854 10672; e-mail: baojinku@yahoo.com.cn

Abbreviations: Fru, fructose; Gal, galactose; GalNAc, N-acetylgalactosamine; Glc, galactose; GlcNAc, N-acetylglucosamine; GNA, Galanthus nivalis agglutinin; HCA, hydrophobic cluster analysis; HIV, human immuno-deficiency virus; LAA, Lycoris aurea agglutinin; LRA, Lycoris radiata agglutinin; MBL, mannose-binding lectin; NHA, Narcissus hybrid cultivar agglutinin; NPA, Narcissus pseudonarcissus agglutinin; PCR, polymerase chain reaction; RACE, rapid amplification of cDNA ends; SDS/PAGE, sodium dodecyl sulfate-polyacrylamide gel electrophoresis; ZGA, Zephyranthes grandiflora agglutinin.
} 
striving to exploit the potent anti-(retro) virus activity with the aim of developing new medicines such as microbicide drugs against HIV. Lectins from the Orchidaceae species, such as Epipactis helleborine agglutinin, have anti-RSV (respiratory syncytial virus) activity in HeLa cells, Cymbidium hybrid agglutinin has anti-CMV (anti-human cytomegalovirus) activity in HEL cells and Listera ovata agglutinin has anti-influenza virus activity in MDCK cells (Van Damme et al., 1994). Moreover, these lectins are highly inhibitory to HIV-I/II in cell culture (Balzarini et al., 1992). Also, lectins from the Amaryllidaceae species Galanthus nivalis, Hippeastrum hybrid and Narcissus pseudonarcissus, inhibit HIV-I/II infections at concentrations in the nanomolar range (Balzarini et al., 2004). Furthermore, lectin from the Amaryllidaceae species $L$. radiata has been cloned and characterized as an MBL with three mannose-binding boxes, similar to other Amaryllidaceae lectins (Zhao et al., 2003; Chang et al., 2005). Extracts from bulbs of the closely related $L$. aurea, which is also a typical representative of the Amaryllidaceae and an important Chinese traditional herbal medicine, have been used as a treatment for skin herpesvirus in Chinese medicine for hundreds of years. Two isolectins have been obtained from the bulbs of $L$. aurea and characterized (Yagi et al., 1993). Interestingly, an antiserum raised against these lectins reacted weakly with other lectins from the Amaryllidaceae, revealing differences in immunological reactivity and making the L. aurea isolectins exceptional among the Amaryllidaceae family lectins (Yagi et al., 1993). Therefore, in this report, we focused on the purification, characterization and molecular cloning of the MBL from the bulbs of $L$. aurea. Molecular cloning of the $L A A$ gene demonstrated that LAA should be considered as a novel member of the monocot MBLs. Molecular modeling and docking experiments showed that LAA is one of the very few lectins, like $N$. pseudonarcissus agglutinin (NPA), which have an additional mannose-binding site near the tryptophan cluster (Sauerborn et al., 1999). This discovery extends our knowledge on protein-carbohydrate recognition, which is much more complex than other recognition processes such as protein-protein or protein-DNA interactions (Loris et al., 2004), and justifies a more detailed evaluation of LAA for its biological (i.e. antiviral) properties.

\section{MATERIALS AND METHODS}

Plant material. Young bulbs of Lycoris aurea collected from Sichuan province, China, in August (florescence), were instantly frozen in liquid nitrogen and preserved at $-70^{\circ} \mathrm{C}$ for RNA extraction.

Protein determination. Protein concentrations were determined as described by Lowry et al. (1951), using crystalline bovine serum albumin as a standard.

Extraction and purification of LAA. Bulbs of L. aurea were homogenized in $0.14 \mathrm{~mol} / \mathrm{L} \mathrm{NaCl}$ in a Waring blender (Philips, Zhuhai, China) at $4^{\circ} \mathrm{C}$. Then the homogenate was centrifuged $(4000 \times g, 10 \mathrm{~min}$, $4^{\circ} \mathrm{C}$ ) and the supernatant was filtered through filter paper (Whatman 3MM, New Jersey, USA). Solid ammonium sulfate was added to the filtered extract at $80 \%$ saturation. The precipitate was collected by centrifugation $(9000 \times \mathrm{g}, 30 \mathrm{~min})$ and then dissolved and dialysed against $50 \mathrm{mmol} / \mathrm{L}$ Tris/ $\mathrm{HCl}$ buffer $(\mathrm{pH}$ 7.4). After another centrifugation $(9000 \times g, 30 \mathrm{~min}$, $4^{\circ} \mathrm{C}$ ) of the dialysate, the supernatant was subjected to fractionation on a DEAE-Sepharose Fast Flow column (Amersham Biosciences, Piscataway, USA) equilibrated with the same buffer. The bound protein was eluted with a linear gradient of $0-1.0 \mathrm{~mol} / \mathrm{L}$ $\mathrm{NaCl}$ in the same buffer and active fractions were pooled and applied to gel filtration on a Sephacryl $\mathrm{S}-100$ column equilibrated with $10 \mathrm{mmol} / \mathrm{L}$ sodium phosphate buffer ( $\mathrm{pH}$ 7.4). After eluting the column with the same sodium phosphate buffer, the main peak with the strongest hemagglutinating activity was collected and lyophilized for further use.

Determination of the molecular mass of LAA. The molecular mass of LAA was estimated by gel filtration chromatography on the same Sephacryl S-100 column mentioned above. The column was calibrated with BSA (66.2 kDa), GNA (48 kDa), pep$\sin (35.5 \mathrm{kDa})$, and trypsin $(23.3 \mathrm{kDa})$. Gel filtrationpurified lectin was subjected to sodium dodecyl sulfate-polyacrylamide gel electrophoresis (SDS/PAGE), $\mathrm{pH} 8.3$, using $12 \%$ separating and $5 \%$ stacking gels for subunit molecular mass determination (Laemmli, 1970).

Hemagglutinating activity and saccharide inhibition assays. Hemagglutinating activity was determined by the method of serial double-dilution. The sugar specificity was determined by comparing the inhibitory activity of hemagglutination in LAA solutions $(25 \mu \mathrm{l})$ which were serially diluted with physiological saline and incubated with various concentrations of $80 \mathrm{mmol} / \mathrm{L}$ carbohydrates or $2 \%$ glycoprotein solution $(25 \mu \mathrm{l})$ for $1 \mathrm{~h}$. The carbohydrates and glycoproteins tested were: mannose, mannan, $\mathrm{N}$-acetylgalactosamine, $\mathrm{N}$-acetylglucosamine, galactose, fructose, glucose, sialic acid, ovalbumin, thyroglobulin.

Amino-acid sequence analysis. The $\mathrm{NH}_{2}$-terminal amino-acid sequence of LAA was determined by automated Edman degradation on an Applied Biosystems model 476A sequencer (Applied Biosystems, Foster City, USA). Phenylthiohydantoin (PTH) amino acids were identified in a $140^{\circ} \mathrm{C}$ microgradient.

RNA and DNA isolation. Bulbs of L. aurea were powdered in liquid nitrogen with a mortar 
and pestles. Total RNA and DNA were isolated using the RNA and DNA Extraction Kit (Takara Biotechnology Co. Ltd) according to the manufacturer's instructions.

3'-RACE (rapid amplification of cDNA ends) and $5^{\prime}$-RACE of $L A A$ gene. CDNA synthesis was performed with the 3'-RACE System (GIBCO BRL, USA). Essentially, RNA was reversely transcribed with a cDNA synthesis primer (5' GGC CAC GCG TCG ACT AGT AC TTTTTTTTTTTTTTTTTTTTT 3'). Degenerate primer 1 (5' TAC TCC/T GGC/T GAG ACT/C CTC TCT/C $3^{\prime}$ ) was designed according to the N-terminal amino-acid sequences of LAA. PCR was performed (denaturing cDNA at $94^{\circ} \mathrm{C}$ for $5 \mathrm{~min}$, then 29 cycles of $94^{\circ} \mathrm{C}$ for $1 \mathrm{~min}, 55^{\circ} \mathrm{C}$ for $1 \mathrm{~min}$, $72^{\circ} \mathrm{C}$ for $2 \mathrm{~min}$, and a final cycle at $72^{\circ} \mathrm{C}$ for $10 \mathrm{~min}$ ). The PCR product was separated by electrophoresis on $1 \%$ agarose gel and purified and cloned into the pMD18-T vector for sequencing.

Based on the sequence of the 3'-RACE product, the specific primers 2 ( $5^{\prime}$ CTG TGG TGC TGA TCC TGG AAG $3^{\prime}$ ) and 3 ( $5^{\prime}$ CCA ACG AGC GGT TCC GTA GAT $3^{\prime}$ ) were designed to amplify the $5^{\prime}$ end of LAA. According to the manufacturer's instructions of SMART ${ }^{\mathrm{TM}}$ RACE cDNA Amplification Kit, RNA was reversely followed by tailing cDNA with the SMART II oligonucleotide. The first round of PCR was performed with primer 2 and SMART III. The PCR product was diluted 50 fold for the second round of amplification with primer 3 and SMART III. The PCR product was purified and cloned into the pUC18-T vector for sequencing.

Generation of full-length $L A A$ cDNA sequence. The sequences of the $3^{\prime}$ and $5^{\prime}$ cDNA ends were aligned to obtain a predicted full-length cDNA. According to the aligned sequence, a pair of specific primers (forward primer 4: 5' C AAA ATG GCT AAG ACA AGT TTC CTC $3^{\prime}$ and reverse primer 5: 5' CTT CAT TAC ACA ACA TGC ATG C 3') was designed to amplify the $L A A$ gene from genomic DNA. PCR was performed according to the conditions used in 3' RACE.

Molecular modeling and docking. Multiple amino-acid sequence alignment was performed using CLUSTAL W (Higgins et al., 1994). Hydrophobic cluster analysis (Gaboriaud et al., 1987; LemesleVarloot et al., 1990) was performed to delineate the structurally conserved $\beta$-sheets along the amino-acid sequence of LAA using NPA as a model. Molecular modelling of LAA was carried out on Swiss-Model 3.5 (http://swissmodel.expasy.org/).

To investigate the docking mode of LAA, we selected the Lamarckian genetic algorithm (LGA) offered by AutoDock 3.0.5 (Solis \& Wets, 1981; Morris et al., 1998) in this study. The grid boxes centered on the selected amino acids (such as QDNYs, W41, etc.) include the entire binding site and provide enough space for the ligand translational and rotational walk. Thirty runs were performed. For each independent run, a maximum number of 27000 LGA operations were generated on a population of 50 individuals. Operator weights for crossover, mutation, and elitism were default parameters $(0.80,0.02$, and 1 , respectively).

\section{RESULTS}

\section{Purification and characterization of the LAA}

The crude extract from bulbs of L. aurea, purified by ion exchange chromatography, yielded two adsorbed peaks (Fig. 1A), one (D1) devoid of hemagglutination activity and the other (D2) exhibiting strong hemagglutinating activity. D2, chromatographed on Sephacryl S-100 (Fig. 1B), yielded a very small peak (Q1) without a hemagglutinating activity and a large peak (Q2) with hemagglutinating activity. This purified lectin exhibited almost the same elution volume as GNA (Fig. 1C), the first described monocot mannose-binding lectin with a molecular mass of $48 \mathrm{kDa}$ in gel filtration (Van Damme et al., 1987) and a single band with a molecular mass of $12 \mathrm{kDa}$ in SDS/PAGE (Fig. 2), indicating that LAA was a tetrameric protein with four identical subunits, which strikingly resembled other MBLs of Amaryllidaceae family.

LAA strongly agglutinated rabbit erythrocytes at a concentration of $0.49 \mu \mathrm{g} / \mathrm{mL}$, but did not agglutinate any type of human erythrocytes even at a concentration of $1 \mathrm{mg} / \mathrm{ml}$. The hemagglutinating activity was specifically inhibited by mannan and thyroglobulin (Table 1). Mannose was able to partly inhibit the hemagglutinating activity. Other sugars did not inhibit the agglutinating activity of LAA.

\section{Cloning of the $L A A$ gene}

Based on thirty successfully sequenced $\mathrm{NH}_{2}$ terminal amino acids (ENILYSGETLSPGDFLSYGSYVFIMQEDCN), primers were designed and RTPCR and RACE were performed. As a result, a 516 bp fragment at the $3^{\prime}$ end and a $411 \mathrm{bp}$ fragment at the $5^{\prime}$ end of $L A A$ were obtained. Through analyzing the $3^{\prime}$-end and $5^{\prime}$-end sequence, the $683 \mathrm{bp}$ full-length cDNA containing a $486 \mathrm{bp}$ open reading frame and encoding a 162 amino-acid protein was obtained. Using the gene-specific primers 4 and 5, the full-length DNA and deduced aminoacid sequences were obtained by PCR on genomic DNA extracted from young bulbs of L. aurea. The nucleic acid sequence and the deduced amino-acid sequences from cDNA and genomic DNA proved 
identical. This indicated that there was no intron in LAA. According to the rules of predicting the signal peptide (Jannick et al., 2004) and in comparison with GNA for which the complete protein was sequenced (Van Damme et al., 1991), a 23-amino acidsignal peptide before S23 and a 30-amino acid-C-
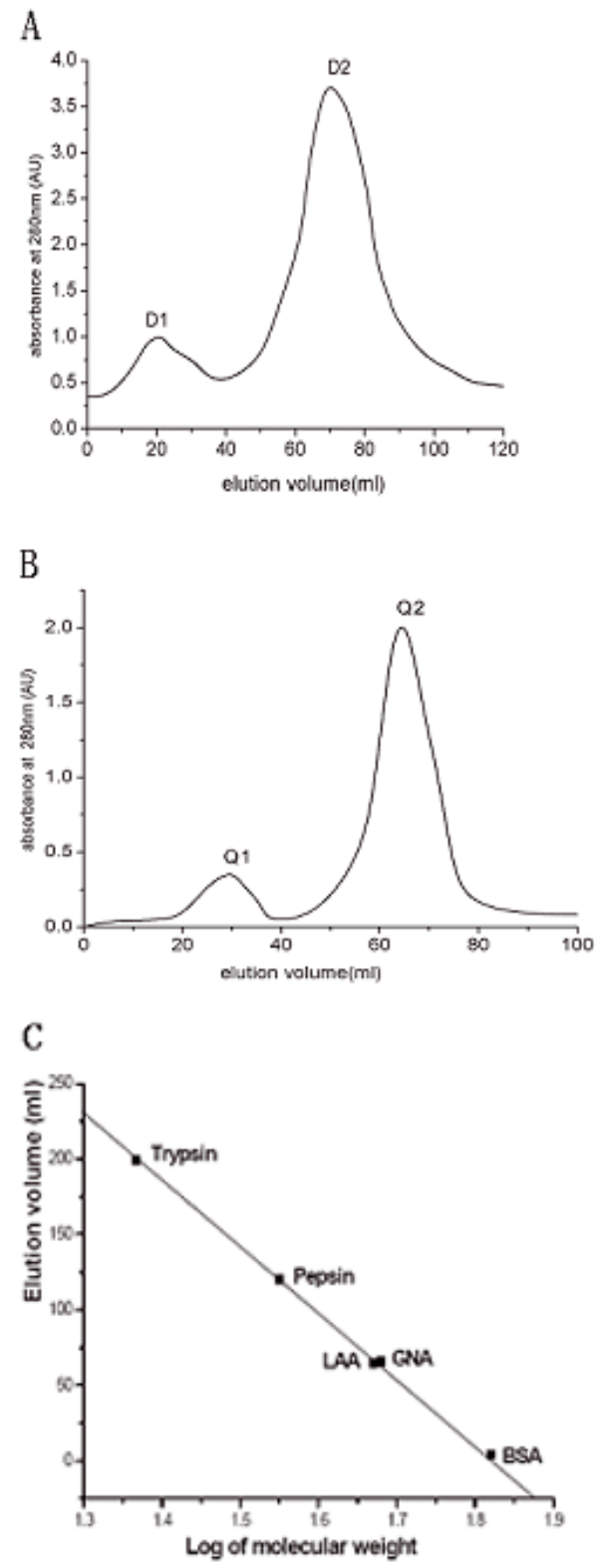

Figure 1. Purification and molecular mass estimation of LAA.

A. Elution profile of LAA on DEAE/Sepharose column pre-equilibrated with Tris/ $\mathrm{HCl}$ buffer ( $\mathrm{pH}$ 7.4). The bound protein was eluted with $0-1.0 \mathrm{~mol} / \mathrm{L} \mathrm{NaCl}$ gradient at a flow rate of $2 \mathrm{ml} / \mathrm{min}$. B. Gel-filtration of active fraction D2 on Sephacryl S-100 column pre-equilibrated with sodium phosphate buffer ( $\mathrm{pH} \mathrm{7.4)}$ at a flow rate of $45 \mathrm{ml} / \mathrm{h}$. The elution profiles were monitored at $280 \mathrm{~nm}$. C. Standards used for gel-filtration analysis were BSA $(66.2 \mathrm{kDa})$, GNA (48 kDa), pepsin (35.5 kDa), and trypsin (23.3 kDa). terminal cleavage peptide after H132 were identified. So, the mature polypeptide LAA contains 109 residues with a theoretic isoelectric point of 4.72 and a calculated molecular mass of $12.1 \mathrm{kDa}$, which is in good agreement with the molecular mass measured by SDS/PAGE.

\section{Homology analysis}

Database retrieval with PSI-Blast (Altschul et al., 1997) showed that LAA is a member of the monocot MBL superfamily. Multi-alignment of LAA with other monocot MBLs revealed that the sequence identity between LAA and N. pseudonarcissus agglutinin (NPA), G. nivalis agglutinin (GNA), N. hybrid cultivar agglutinin (NHA), L. radiata agglutinin (LRA) and Zephyranthes grandiflora agglutinin (ZGA) were $88.99 \%, 82.57 \%, 83.49 \%, 79.09 \%$ and $80.91 \%$, respectively (Fig. 3). Like many other monocot MBLs, LAA monomer also has three mannose-binding sites (QDNY) (Fig. 3).

\section{Modeling and docking of LAA}

Considering the highest identity $(88.99 \%)$ between the amino-acid sequences, the coordinates of NPA (Sauerborn et al., 1999) were selected as the model. Most of the buried residues of the polypeptides of both lectins are readily conserved (Fig. 3). A comparison of their HCA plots (Fig. 4) allowed an easy delineation along the amino-acid sequence of LAA of the twelve strands of the $\beta$-sheet present in NPA (Gaboriaud et al., 1987; Lemesle-Varloot et al., 1990). The three-dimensional model of LAA strongly resembles that of NPA (Fig. 5). Each subdomain contains a mannose-binding site of four conserved amino-acid residues (QDNY), which binds mannose through a network of four hydrogen bonds interconnecting the hydroxyls $\mathrm{C} 2-\mathrm{OH}, \mathrm{C} 3-\mathrm{OH}$ and $\mathrm{C} 4-\mathrm{OH}$ of mannose to the four residues (Hester et al., 1995; Hester \& Wright, 1996; Sauerborn et al., 1999). Furthermore, a valine residue, which interacts with C3

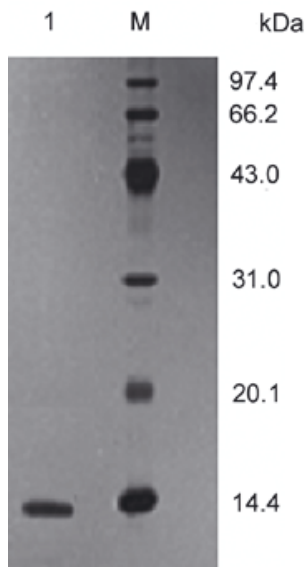

Figure 2. SDS/PAGE analysis of purified LAA.

Lane 1, purified LAA $(30 \mu \mathrm{g})$. Lane $\mathrm{M}$, molecular mass markers. The mass markers used were: rabbit phosphorylase $\mathrm{B}$ (97.4 kDa), bovine serum albumin $(66.2 \mathrm{kDa})$, rabbit actin $(43.0 \mathrm{kDa})$, bovine carbonic anhydrase $(31.0 \mathrm{kDa})$, trypsin inhibitor (20.1 kDa), hen egg white lysozyme (14.4 kDa); the gels were stained with Coomassie Brilliant Blue. 
Table 1. Inhibition of hemagglutination of LAA by carbohydrates and glycoproteins

\begin{tabular}{|c|c|c|c|c|c|c|c|c|c|c|c|}
\hline \multirow[t]{2}{*}{ Carbohydrates $(80 \mathrm{mmol} / \mathrm{L})$} & \multicolumn{11}{|c|}{ LAA concentration $(\mu \mathrm{g} / \mathrm{mL})$} \\
\hline & 500 & 250 & 125 & 62.5 & 31.3 & 15.6 & 7.80 & 3.90 & 1.95 & 0.98 & 0.49 \\
\hline Control & + & + & + & + & + & + & + & + & + & + & + \\
\hline Mannose & + & + & + & + & - & - & - & - & - & - & - \\
\hline Mannan & - & - & - & - & - & - & - & - & - & - & - \\
\hline Gal & + & + & + & + & + & + & + & + & + & + & - \\
\hline GalNAc & + & + & + & + & + & + & + & + & + & + & - \\
\hline Fru & + & + & + & + & + & + & + & + & + & + & - \\
\hline Glc & + & + & + & + & + & + & + & + & + & + & - \\
\hline GlcNAc & + & + & + & + & + & + & + & + & + & + & - \\
\hline Sialic acid & + & + & + & + & + & + & + & + & - & - & - \\
\hline Thyroglobulin (2\%) & - & - & - & - & - & - & - & - & - & - & - \\
\hline Ovalbumin $(2 \%)$ & + & + & + & + & + & + & + & + & + & + & + \\
\hline
\end{tabular}

Note: +, agglutination; -, no agglutination

and C4 of mannose through van der Waals interactions, is also conserved in each subdomain of both NPA and LAA.

Interestingly, a fourth binding site observed in NPA may also exist in LAA (Fig. 5C). This unique site of NPA, using a tryptophan cluster to make contacts with carbohydrates, is difficult to describe in terms of sequence (Sauerborn et al., 1999). As the docking experiment shows, the mannose molecule could have two alternative conformations $(\mathrm{RMSD}=5.6940 \AA$ ) (Fig. 5D). In the conformations $\alpha$ and $\beta$, the binding energies are $-3.81 \mathrm{kcal} / \mathrm{mol}$ and $-3.37 \mathrm{kcal} / \mathrm{mol}$, respectively, while the docking energies are $-4.42 \mathrm{kcal} / \mathrm{mol}$ and $-3.79 \mathrm{kcal} / \mathrm{mol}$, respectively. In both conformations, mannose sits in a cleft on the LAA surface.

\section{DISCUSSION}

This report describes a biochemical and molecular biological study of the MBL from L. aurea. Based on carbohydrate inhibition assays and analysis of the corresponding gene it was revealed that LAA belongs to the superfamily of monocot MBL. The agglutination reaction of LAA with various types of blood cells revealed that it can only agglutinate rabbit red blood cells but not human erythrocytes. Using protein purification techniques, we demonstrate that LAA is a tetrameric protein composed of four identical subunits of about $12 \mathrm{kDa}$. The two isolectins Yagi and coworkers purified in 1993 from Japanese L. aurea were both pure dimers which were both estimated to be $25 \mathrm{kDa}$ by gel filtration and

\footnotetext{
LAA (1) ENILYSGETLSPGDFLSYGSYVFIM EEDCNLVLYNVDKPIWATNTGGLSR

NPA (1) DNILYSGETLSPGEFLNNGRYVFIMQEDCNLVLYDVDKPIWATNTGGLDR

GNA (1) DNILYSGETLSTGEFLNYGSFVFIMQEDCNLVLYDVDKPIWATNTGGLSR

ZGA (1) DNILYSGETLSTGES FNYGPYTFIMQEDCNLVLYDVDKPIWASNTGGLAR

NHA (1) DNILYSGDTLSTGQFLSYGSYVFIMQEDCNLVLYDVDKPIWATNTGGLSS

LRA (1) DNILHSGKTLSPGEFLSYRSYVFIMQEDCNLVLYDVDKPIWATNTGGLSS

Consensus (1) DNILYSGETLS GEFLNYG YVFIMQEDCNLVLYDVDKPIWATNTGGLSR

$51 \quad 100$

LAA (51) DCHLSM QSDGNLVVYSRQ-NKPIWASDTGGENG-NYVCVLQKDRNVVIYG

NPA (51) RCHLSMQSDGNLVVYSPR-NNPIWASNTGGENG-NYVCVLQKDRNVVIYG

GNA (51) SCFLSMQTDGNLVVYNPS-NKPIWASNTGGQNG-NYVCILQKDRNVVIYG

ZGA (51) GCHLSMQSDGNLVVYTPSGNRAIWASNTQGENG-NYVCILQKDRNVVIYG

NHA (51) DCHLSMQTDGNLVVYSPQ-NKAIWASNTDGENG-HFVCILQKDRNVVIYG

LRA (51) GCHLSMQSDGNLVVYSPQ-NRPIWASDTGGQNDANYVLILQKDRNVVIYG

Consensus (51) GCHLSMQSDGNLVVYSP NRPIWASNT GENG NYVCILQKDRNVVIYG $101 \quad 111$

LAA (99) TARWATGTNIH

NPA (99) TARWATGTNIH

GNA (99) TDRWATGTHTG

ZGA (100) TARWATGTNIH

NHA (99) TDRWATGTYTG

LRA (100) PATLGHWNLHR

Consensus (101) TARWATGT

Figure 3. Multi-alignment of the predicted LAA amino-acid sequence with other monocot mannosebinding lectins.

Mannose-binding sites (QDNY) are boxed.
} 


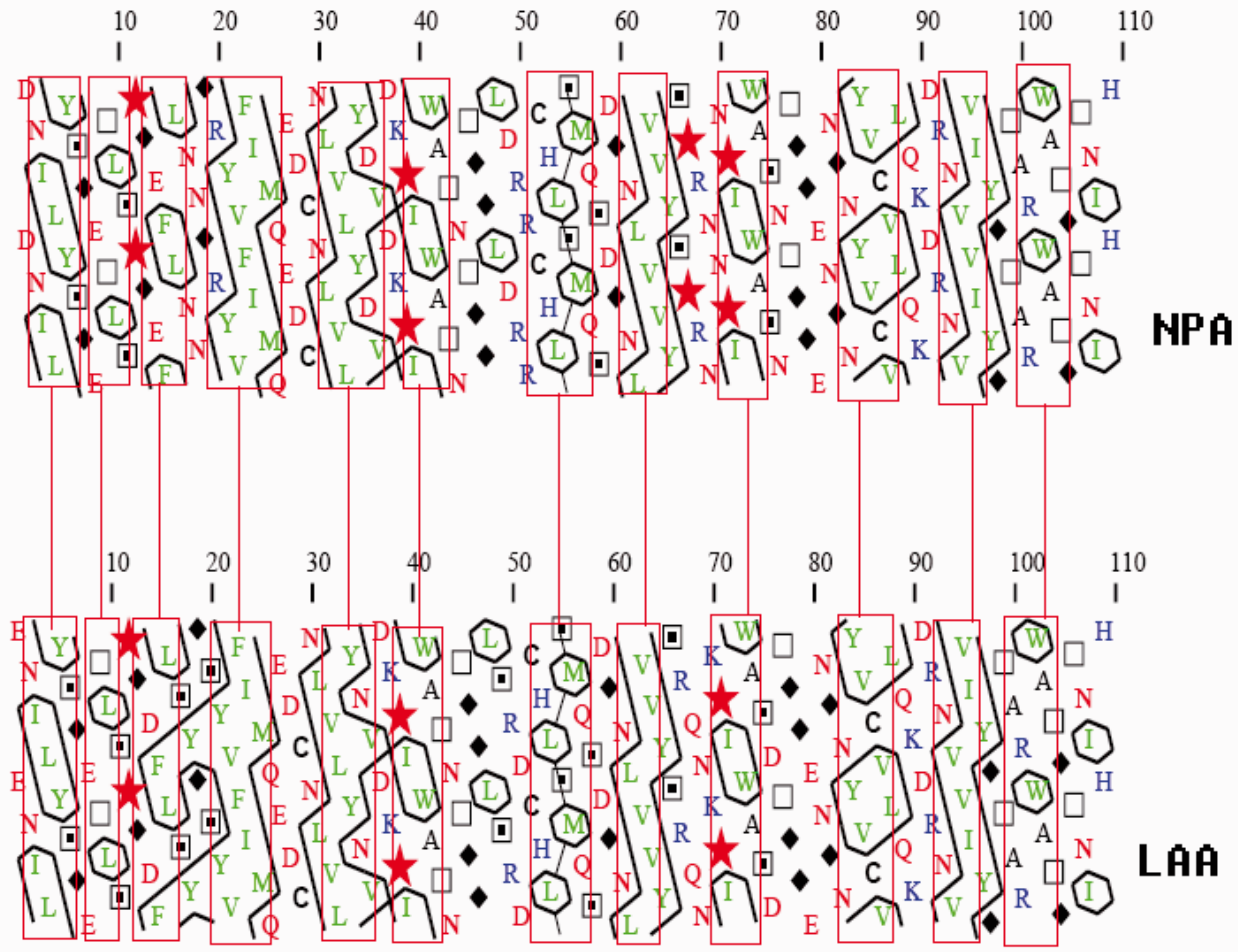

Figure 4. Comparison of predicted HCA plots of NPA (upper) and LAA (lower).

The structurally conserved regions which exhibit similar conserved hydrophobic properties between LAA and HCA are encircled in bold line.
$12 \mathrm{kDa}$ by SDS/PAGE. Only 15 amino acids at the $\mathrm{N}$-terminus of the two dimers were sequenced, and we found that the fourteenth residue from the N-terminus of the subunit in our tetrameric protein was aspartic acid, whereas the dimeric counterpart had a glutamic acid. As no data is available about the full sequence of the two dimers of Yagi and coworkres no further sequence comparison between the dimers and the tetramer is feasible. It is possible that both the dimers and the tetramer are isolectins. The different environment between Kagoshima, Japan, and Chengdu, China may contribute to the differences between the lectins. The discovery of this new gene should encourage research in many fields, like the evolutionary relationships among the MBLs, the function of MBLs in plant physiology, and so on.

Analysis of the LAA sequence revealed the presence of three absolutely conserved mannosebinding sites (QDNY). Interestingly, the multiple alignment revealed the highest identity between LAA and NPA (88.99\%) but not LRA, which, traditionaly, is thought to be much closer to LAA in evolution. Using a homology model program, we obtained a three-dimensional structure of LAA which strongly resembles that of NPA. Surprisingly, further docking analysis showed a fourth carbohydraterecognizing domain that existed near the tryptophan cluster and that might be involved in the recognition of naturally occurring glycans (Sauerborn et al., 1999). As to our knowledge, LAA is the second monocot MBL discovered to date which has four mannose-binding domains. Therefore, further struc- tural research on LAA should enable discovering a new mode of interaction between mannose and such monocot MBLs.

It has been demonstrated that the gp120 envelope of HIV-I contains approx. 50\% of high-mannose-type oligosaccharides: all 24 N-linked glycosylation sites are utilized in $\mathrm{HIV}-1\left(\mathrm{III}_{\mathrm{B}}\right)$ gp120; 11 contain hybrid and/or high-mannose-type structures while 13 of the glycosylation sites contain complextype oligosaccharides. Balzarini et al. (1991; 2004) reported that the $\alpha$-(1-3)-D-mannose- and $\alpha-(1-6)-\mathrm{D}-$ mannose-specific agglutinins from Galanthus nivalis, Hippeastrum hybrid, Narcissus pseudonarcissus and Listera ovata inhibited infection of MT-4 and CEM cells by HIV I/II. Also, the mannose-binding lectin LRA, which is closely related to LAA, was found inhibitory against HIV-1 and HIV-2 at $0.29-0.43$ and $0.59-0.60 \mu \mathrm{g} / \mathrm{ml}$, respectively, in MT-4 and CEM cell cultures, being virtually non-toxic at $100 \mu \mathrm{g} / \mathrm{ml}$ (An et al., 2006). López et al. (2003) reported an anti-HIVI activity of mannose-specific lectins from Narcissus species and showed that the anti-HIV activity of $N$. tortifolious lectin was 10- (in $\mu \mathrm{g} / \mathrm{mL}$ ) and 100- (in molarity)-fold more potent than that of the polyanion dextran sulfate, an HIV entry inhibitor. Thus, plant lectins may be considered as most interesting agents that potently inhibit HIV entry into its target cells. In addition, LAA exhibits no significant cytotoxicity towards T-lymphocyte CEM cells and simian kidney Vero cells (unpublished data). Therefore, it now seems imperative to evaluate LAA for its antiviral potential and to compare its antiviral activity 

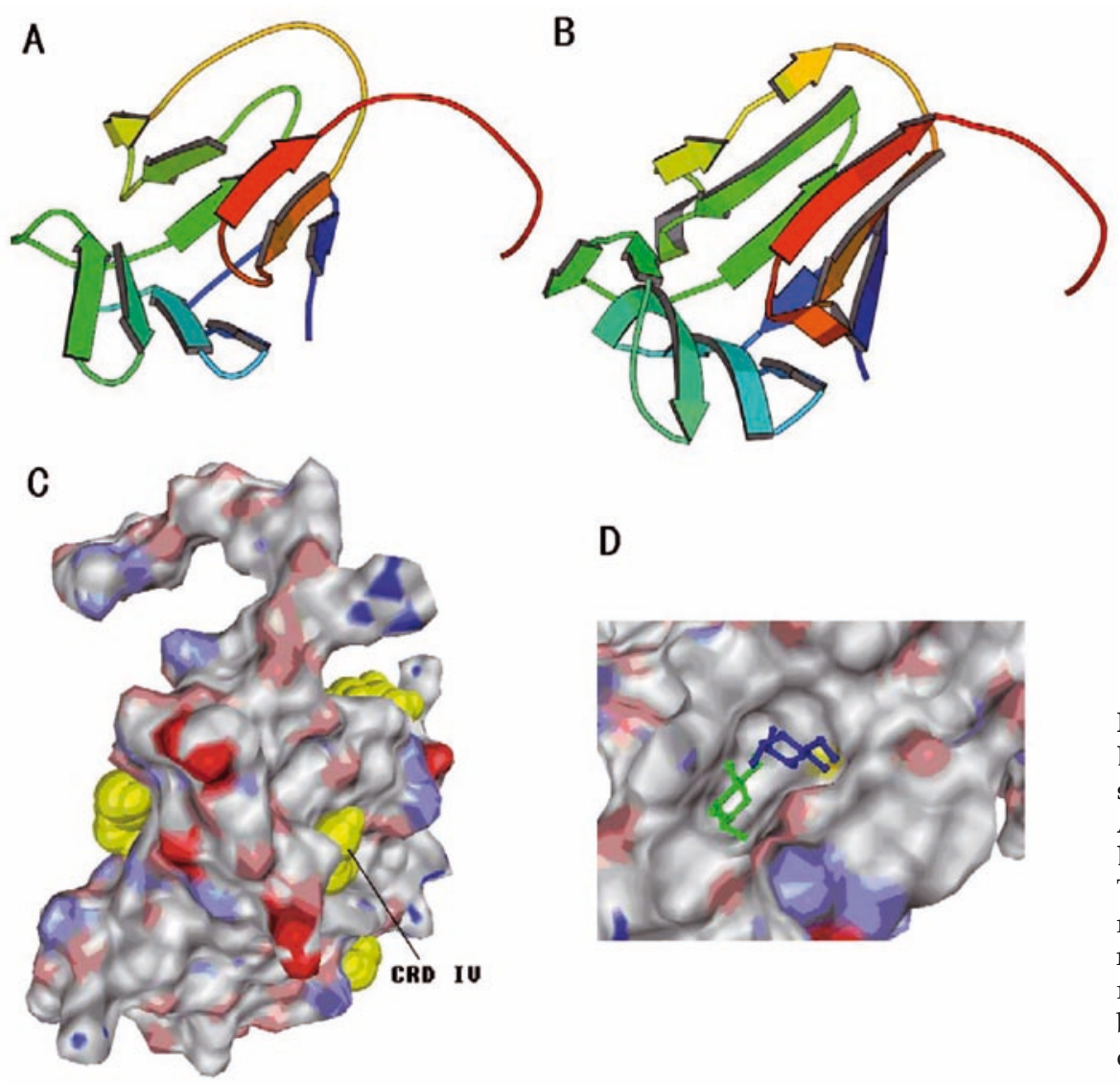

D

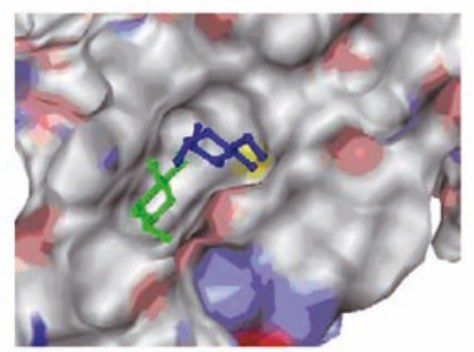

Figure 5. Tertiary structure of LAA and its mannose-binding sites.

A. Structure of NPA monomer. B. Structure of LAA monmer. C. The molecular surface of LAA monomer and its binding to mannose. D. The CRD (carbohydrate recognizing domain) IV and the binding to mannose, mannose in conformation $\alpha$ is green and in conformation $\beta$ is blue.

(not limited to HIV, but including other enveloped viruses) with those mannose-specific lectins that do not contain the fourth mannose-binding site in the monomers.

\section{Acknowledgements}

This work was supported by grants from the National Natural Sciences Foundation of China (No. 30000032 and 30270331). This work was also supported by the European Commission (EMPRO) and the Centers of Excellence of the $\mathrm{K}$. U. Leuven (EF/05/15) (to J.B.).

\section{REFERENCE}

Altschul SF, Madden TL, Schaffer AA, Zhang J, Miller W, Lipman DJ (1997) Gapped BLAST and PSI-BLAST: a new generation of protein database search programs. Nucleic Acids Res 25: 3389-3402.

An J, Liu J-z, Wu C-f, Li J, Dai L, Van Damme E, Balzarini J, De Clercq E, Chen F, Bao J-k (2006) Anti-HIV I/II activity and molecular cloning of a novel mannose/sialic acid-binding lectin from rhizome of Polygonatum cyrtonema Hua. Acta Biochim Bioph Sinica 38: 70-78.

Balzarini J, Schols D, Neyts J, Van Damme E, Peumans W, De Clercq E (1991) $\alpha$-(1-3)- and $\alpha$-(1-6)-D-mannosespecific plant lectins are markedly inhibitory to human immunodeficiency virus and cytomegalovirus infections in vitro. Antimicrob Agents Chemother 35: 410-416.

Balzarini J, Neyts J, Schols D, Hosoya M, Van Damme E, Peumans W, De Clercq E (1992) The mannose-specfic plant lectins from Cymbidium hybrid and Epipactis helleborine and the ( $\mathrm{N}$-acetylglucosamine)n-specfic plant lectin from Urtica dioica are potent and selective inhibitors of human immunodeficiency virus and cytomegalovirus replication in vitro. Antiviral Res 18: 191-207.

Balzarini J, Hatse S, Vermeire K, Princen K, Aquaro S, Perno C-F, De Clercq E, Egberink H, Vanden Mooter G, Peumans W, Vandamme E, Schols D (2004) Mannose-specific plant lectins from the Amaryllidaceae family qualify as efficient microbicides for prevention of human immunodeficiency virus infection. Antimicrob Agents Chemother 48: 3858-3870.

Barre A, Van Damme EJM, Peumans WJ, Rougé P (1996) Structure-function relationship of monocot mannosebinding lectins. Plant Physiol 112: 1531-1540.

Bendtsen JD, Nielsen H, von Heijne G, Brunak S (2004) Improved prediction of signal peptides: SignalP 3.0. J Mol Biol 340: 783-795.

Chang LQ, Wu CF, LU HZ, Liu C, Gu Y, Chen F, Wu QQ, Bao JK (2005) Purification and characterization of agglutinin from bulbs of Lycoris radiate (Amarylidaceae). Chinese journal of applied and environmental biology. 11: 164-167.

Gaboriaud C, Bissery V, Benchetrit T, Mornon JP (1987) Hydrophobic cluster analysis: an efficient new way to compare and analyse amino acid sequences. FEBS Lett 224: 149-155.

Hester G, Kaku H, Goldstein IJ, Wright CS (1995) Structure of mannose-specific snowdrop (Galanthus nivalis) 
lectin is representative of a new plant lectin family. Nat Struct Biol 2 472-479.

Hester G, Wright CS (1996) The mannose-specific bulb lectin from Galanthus nivalis (Snowdrop) binds mono- and dimannosides at distinct sites Structure analysis of refined complexes at $2.3 \AA$ and $3.0 \AA$ resolution. J Mol Biol 262: 516-531.

Higgins D, Thompson J, Gibson T, Thompson JD, Higgins DG, Gibson TJ (1994) CLUSTAL W: improving the sensitivity of progressive multiple sequence alignment through sequence weighting, position-specific gap penalties and weight matrix choice. Nucleic Acids Res 22: 4673-4680.

Laemmli HK (1970) Cleavage of structural proteins during the assembly of the head of bacteriophage $\mathrm{T}_{4}$. Nature 227: 680-685.

Lemesle-Varloot L, Henrissat B, Gaboriaud C, Bissery V, Morgat A, Mornon JP (1990) Hydrophobic cluster analysis: procedure to derive structural and functional information from 2-D representation of protein sequences. Biochimie 72: 555-574.

Loris R, Van Walle I, De Greve H, Beeckmans S, Deboeck F, Wyns L, Bouckaert J (2004) Structural basis of oligomannose recognition by the Pterocarpus angolensis seed lectin. J Mol Biol 11: 1227-1240.

Lowry OH, Rosebrough NJ, Farr AL, Randall RJ (1951) Protein measurement with the Folin phenol reagent. J Biol Chem 193: 265-275.

López S, Armand-Úgon M, Bastida J, Viladomat F, Esté JA, Stewart D, Codina C (2003) Anti-human immunodeficiency virus type 1 (HIV-I) activity of lectins from Narcissus species. Planta Med 69: 109-112.

Morris GM, Goodsell DS, Halliday RS, Huey R, Hart WE, Belew RK, Olson AJ (1998) Automated docking using a Lamarckian genetic algorithm and and empirical binding free energy function. J Comput Chem 19: 1639-1662.
Sauerborn MK, Wright LM, Reynolds CD, Grossmann JG, Rizkallah PJ (1999) Insights into carbohydrate recognition by Narcissus pseudonarcissus lectin: the crystal structure at $2 \AA$ resolution in complex with $\alpha 1-3$ mannobiose. J Mol Biol 290: 185-199.

Solis FJ, Wets RJ-B (1981) Minimization by random search techniques. Math Oper Res 6: 19-30.

Van Damme EJM, Allen AK, Peumans WJ (1987) Isolation and characterization of a lectin with exclusive specificity towards mannose from snowdrop (Galanthus nivalis) bulbs. FEBS Lett 215: 140-144.

Van Damme EJM, De Clercq N, Claessens F, Hemschoote K, Peeters B, Peumans WJ (1991) Molecular cloning and characterization of multiple isoforms of the snowdrop (Galanthus nivalis L.) lectin. Planta 186: 35-43.

Van Damme EJM, Smeets K, Torrekens S, Van Leuven F, Peumans WJ (1994) Characterization and molecular cloning of the mannose-binding lectins form three Orchidaceae species: Listera ovata, Epipactis helleborine and Cymbidium hybrid. Eur J Biochem 221: 769-777.

Van Damme EJM, Peumans WJ, Barre A, Rougé P (1998) Plant lectins: A composite of several distinct families of structurally and evolutionary related proteins with diverse biological roles. Crit Rev Plant Sci 17: 645-662.

Van Damme EJ, Astoul C, Barre A, Rougé AP, Peumans WJ (2000) Cloning and characterization of a monocot mannose-binding lectin from Crocus vernus (family Iridaceae). Eur J Biochem 267: 5067-5077.

Yagi F, Noguchi S, Suzuki S, Tadera K, Goldstein IJ (1993) Purification and characterization of isolectins from Lycoris aurea. Plant Cell Physiol 34: 1267-1274.

Zhao X, Yao J, Sun X, Tang K (2003) Molecular cloning and characterization of a novel lectin gene from Lycoris radiate. DNA Seq 14: 223-226. 